\title{
Inferior Lumbar Hernia: Case report
}

\author{
Dr Manish kr Singh, Dr Alok Kumar, Dr Prof Subrata Nag
}

\begin{abstract}
Introduction: Inferior Lumbar hernia is a rare abdominal hernia and clinical suspicion is necessary for diagnosis.

Case presentation: We report the case of a 35-year-old lady with a reducible inferior lumbar hernia. The hernia was repaired with prolene mesh. The patient was free of recurrence at 6 months after the operation.

Conclusion: A lumbar or flank mass should always raise suspicion of a lumbar hernia. Adequate surgical treatment should be planned on the basis of etiology and hernia size. Both open and laparoscopic techniques can be used with good results
\end{abstract}

\section{Introduction}

Lumbar hernias are rare defects involving two weak areas of the posterolateral abdominal wall: the superior lumbar triangle of Grynfeltt, which is the most common site, and the inferior lumbar triangle of Petit. In large congenital or postsurgical hernias the defect wall can affect the entire lumbar region. Lower-back pain is the most common symptom although small hernias may be asymptomatic except for a palpable mass. Misdiagnosis with subcutaneous lipoma is possible. Adequate surgical treatment depends largely on the type and size of the hernia and both open and laparoscopic techniques can be used with good results.

\section{Case Report}

A 35 year old lady presented to the surgical OPD with complains of swelling in right lumbar region associated with dull aching pain for last 8-9 months. The swelling used to appear on coughing and disappear on compressing it. There was no history suggestive of irreducibility. There was also no history of trauma, surgery done in past or localized muscular paralysis.On examination there was a single oval swelling of 30 x $20 \mathrm{cms}$ arising from the inferior lumbar triangle with an expansile impulse on coughing( Fig 1 ). It was non tender and reducible with a gurgle.The abdominal wall defect was $8 \times 5 \mathrm{cms}$ (Fig 2). The opposite side lumbar region and other hernial orifices were normal. The abdominal muscle tone was good.Patient was thoroughly investigated, Anaesthesia fitness and consent was taken.Right lumbar preperitoneal prolene meshplasty with few stabilization sutures with prolene was done (Fig 3). The patient was well on follow up with no recurrence.

\section{Discussion}

Lumbar hernias are rare and a recent review reported approximately 300 cases [1]. They are classified as congenital, generally associated with other malformations, or acquired, manifesting in adults spontaneously or secondary to trauma or surgical incision [2].Lumbar hernia may occur in two weak areas of the posterolateral abdominal wall: the superior lumbar triangle of Grynfeltt, which is the more common site, and the inferior lumbar triangle of Petit. In large hernias the defect wall can affect all of the lumbar region $[\underline{3}, \underline{4}]$.Symptomatology frequently consists of only lower back pain. Small hernias may be asymptomatic except for a palpable mass. In less than $10 \%$ of cases, the onset is acute with bowel obstruction[트, $\underline{6}$. Anamnesis is helpful for diagnosis in post-traumatic or postsurgical lumbar hernias while in spontaneous adult hernias, misdiagnosis may occur [1, 1$]$.Clinical suspicion is fundamental to guide imaging diagnosis because extraperitoneal fat herniated through a wall defect may mimic a lipoma. Computed tomography (CT) or magnetic resonance imaging (MRI) in patients with a suspected hernia can confirm the diagnosis adding information on parietal defect size, hernia content and muscular trophism []]. In our case since defect was large , so there was no need of CT or MRI. Adequate surgical treatment depends largely on the type and size of the hernia. A single surgeon cannot gain great experience in this pathology but knowledge gained in treatment of other abdominal wall hernias helps in proper planning of surgery. Both open and laparoscopic techniques can be used with good results [9]. Anterior repair is appropriate for repairing recurrent or large defects with a double mesh or a gluteus aponeurosis flap [10]. Laparoscopic repair has been used successfully in different reports with less pain, shortened hospital stay and good cosmetic and functional results [11-13].

\section{Conclusion}

Although a rare pathology, knowledge of lumbar hernia is important to avoid misdiagnosis. In particular, a lumbar or flank mass should always raise suspicion of a lumbar hernia. Ultrasound and CT may confirm the diagnosis. Appropriate surgical treatment should be planned on the basis of etiology and hernia size. 


\section{References}

[1]. Moreno Egea A, Baena EG: Controversies in the current management of lumbar hernias.Arch Surg 2007, 142:82-88.

[2]. Le Neel JC, Sartre JY, Borde L, Guiberteau B, Bourseau JC: Lumbar hernias in adults. Apropos of 4 cases and review of the literature.J Chir (Paris) 1993, 130(10):397-402.

[3]. Loukas M, El-Zammar D, Shoja MM, Tubbs RS, Zhan L, Protyniak B, Krutoshinskaya Y: The clinical anatomy of the triangle of Grynfeltt.Hernia 2008, 12(3):227-231.

[4]. Zhou X, Nve JO, Chen G: Lumbar hernia; Clinical analysis of 11 cases.Hernia 2004, 8:260-263.

[5]. Astracioglu H, Sokmen S, Atila K, Karademir S: Incarcerated inferior lumbar (Petit's) hernia.Hernia 2003, 7:158-160.

[6]. Losanoff EJ, Kjossev KT: Diagnosis and treatment of primary incarcerated lumbar hernia.Eur J Surg 2002, 168:193-195.

[7]. Walsh M, Springfield DS: Spontaneous lumbar hernia.JBJS 2004, 86:1525-1527.

[8]. Killen KL, Girard S, DeMeo JH: Using CT to diagnose traumatic lumbar hernia.AJR 2000, 174:1413-1415.

[9]. Cavallaro G, Sadighi A, Miceli M, Burza A, Carbone G, Cavallaro A: Primary lumbar hernia repair: the open approach.Eur Surg Res 2007, 39(2):88-92.

[10]. Di Carlo I, Toro A, Sparatore F, Corsale G: Lumbar hernia repair using a new technique.Am Surg 2007, 73:54-57.

[11]. Moreno Egea A, Torralba JA, Morales G: Open versus laparoscopic of secondary lumbar hernias: a prospective non randomized trial.Surg Endosc 2005, 19:184-187.

[12]. Moreno Egea A, Guzman P, Girela E, Corral M, Aguayo Albasini GL: Laparoscopic hernioplasty in secondary lumbar hernias.J Laparoendosc Adv Surg Tech A 2006, 16(6):572-576.

[13]. Madan AK, Ternovist CA, Speck KE, Pritchard FE, Thichansky DS: Laparoscopic lumbar hernia repair. Am Surg 2006, 72(4):318-321.
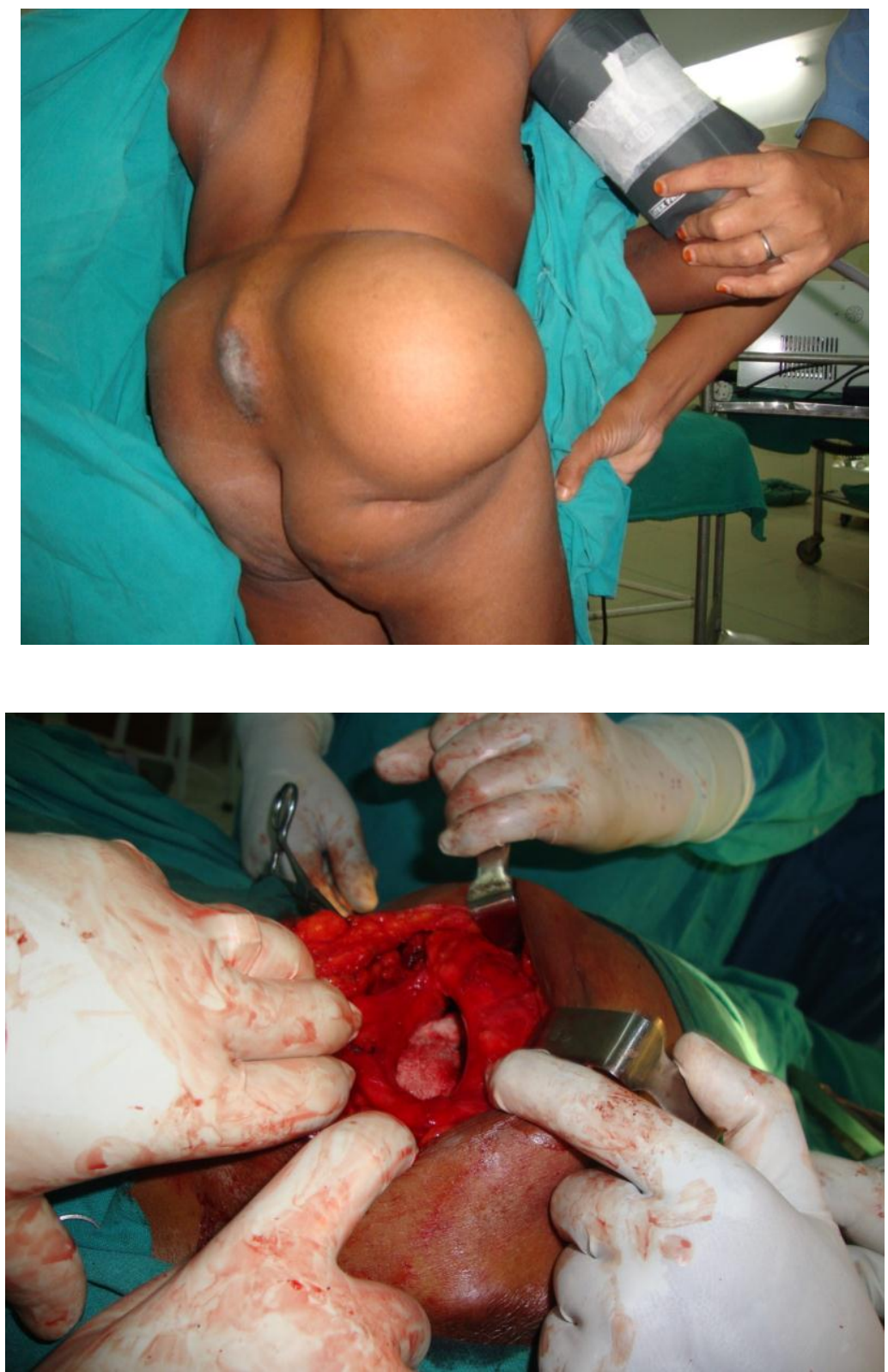


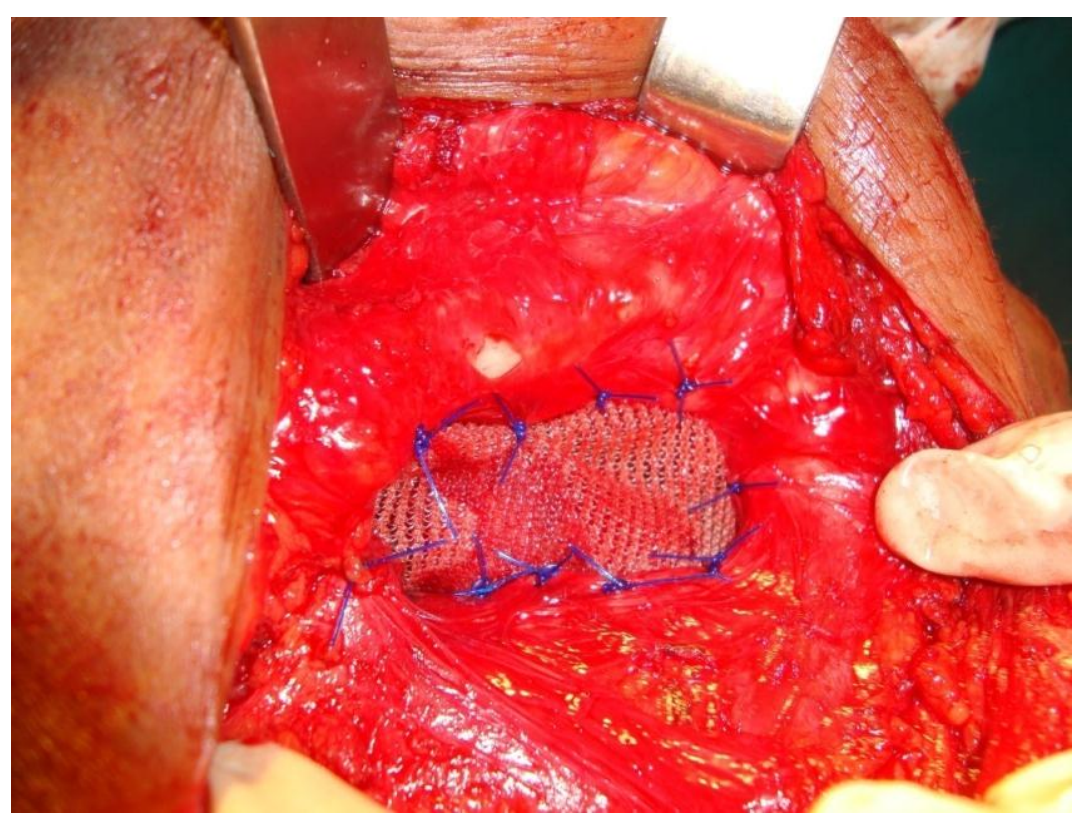

